\title{
Hereditary Breast and Ovarian Cancer Syndrome
}

National Cancer Institute

\section{Source}

National Cancer Institute. Hereditary Breast and Ovarian Cancer Syndrome. NCI

Thesaurus. Code C8493.

An autosomal dominant inherited syndrome caused by mutations in the BRCA1 or BRCA2 genes. Patients are at high risk of developing breast cancer, particularly before the age of fifty, high risk of developing a second primary breast cancer, and high risk of developing both breast and ovarian cancer. 